\title{
University Education for Physical Education Students at Pedagogical Faculties in the Czech Republic - New Findings about First Aid for Spinal Injury
}

\author{
Ladislav Pysny ${ }^{1} \nless$ \\ Jana Pysna? ${ }^{2}$ (D) \\ Dominika Petru ${ }^{3}$ \\ Karol Görner ${ }^{4}$ \\ ${ }^{1,2, s}$ Faculty of Education, Jan Evangelista Purkyně University, Czech Republic \\ Email:l.pysny@seznam.cz \\ ${ }^{4}$ Faculty of Arts, Matej Bel University, Slovakia
}

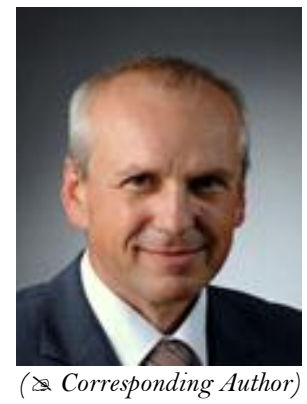

\begin{abstract}
Teaching physical education and sports at pedagogical faculties in the Czech Republic is often associated with certain risks which could lead to acute sports injuries. The most serious of these is traumatic spinal injury that could, in the case of poorly executed first aid, lead to serious damage to the health of individuals, including further unsolvable permanent consequences. Therefore every teacher or trainer as well as every student of physical education and sports must gain the necessary expertise in this field. This paper summarizes new findings about premedical first aid executed when a traumatic spinal injury occurs. It focuses especially on the appropriate assessment of disabilities according to Frankel and the implementation of specific procedures which can solve the trauma in various situations, including the use of a system for extricating an injured victim with a spinal fixation.
\end{abstract}

Keywords: Spine injuries, First aid, Education.

Citation | Ladislav Pysny; Jana Pysna; Dominika Petru; Karol Görner (2017). University Education for Physical Education Students at Pedagogical Faculties in the Czech Republic - new Findings about First Aid for Spinal Injury. Asian Journal of Education and Training, 3(2): 131-134.

History:

Received: 24 November 2017

Revised: 12 December 2017

Accepted: 19 December 2017

Published: 27 Decerber 2017

Licensed: This work is licensed under a Creative Commons

Licensed: This work is
Attribution 3.0 License (cc) E

Publisher:Asian Online Journal Publishing Group
Contribution/Acknowledgement: All authors contributed to the conception and design of the study.

Funding: This study received no specific financial support.

Competing Interests: The authors declare that they have no conflict of interests.

Transparency: The authors confirm that the manuscript is an honest, accurate, and transparent account of the study was reported; that no vital features of the study have been omitted; and that any discrepancies from the study as planned have been explained.

Ethical: This study follows all ethical practices during writing

\section{Contents}

1. Introduction

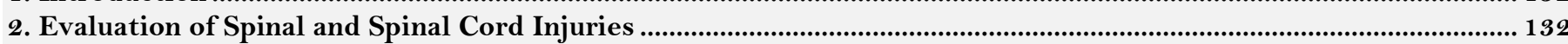

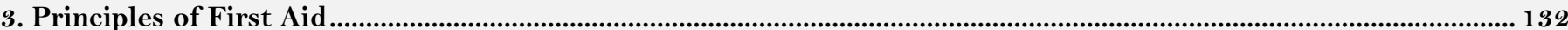

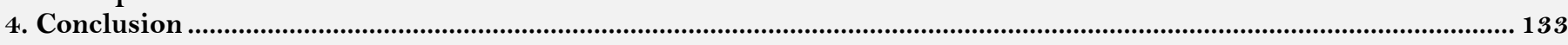

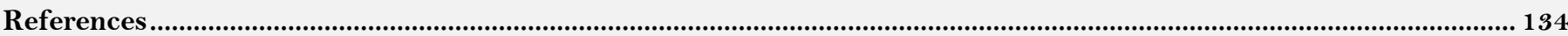




\section{Introduction}

Teaching physical education and sports in the Czech Republic very often includes some physical activities that may be associated with the development of acute injuries to the musculoskeletal system. One of the most serious injuries is spinal trauma, which can occur during almost any sporting activity. Even more risky are special courses such as artistic gymnastics, biking, climbing or hiking. When teaching, the result of poorly performed physical activities may be an injury, which if not treated properly, may lead to serious permanent consequences (for example Patel et al. (2013)). Despite the tremendous mobility of the spine, which is provided by each and every single vertebra, it may lead to damage depending on the formation mechanism and the intensity of the stimulus. The result of structural change may be only ligament damage /stretch, tear or rupture/ or minor tearing of the intervertebral discs. Unfortunately, too often, we may encounter severe subluxation, luxation or fracture of one or more vertebrae (Donatelli et al., 2012). In the area of the cervical spine, the typical type of injury associated with extension is whiplash (Yoganandan et al., 2013). In the area of the thoracic spine, typical damage results from a direct impact (strike, hitting an obstacle with the back) and for the lumbar spine, it is usually an impact on the buttocks or legs during a fall. If the spinal injuries are associated with structural changes of the vertebra, a fragment, especially from the rear part, very often pushes into the spinal canal and may also simultaneously lead to a spinal cord injury / concussion of spinal cord, compression or extension with consequent cracking and bleeding/.

\section{Evaluation of Spinal and Spinal Cord Injuries}

While evaluating the severity of these injuries, we observe local signs of damage such as abrasions, swelling and a hematoma. We simultaneously evaluate percussion and palpation pain above the vertebrae thorns and their distance and position in an upright posture ( $\mathrm{O}^{\prime}$ Dowd, 2007). When a spinal cord injury occurs we may find same changes related to the extent and type of the spinal injury. The changes found when injuries occur may be functional, reversible /concussion only causes spinal concussion/, incompletely reversible /swelling or bleeding leads to spinal cord contusion/, or irreversible disruption of the spinal cord (Vaverka and Hrabálek, 2002).

The most commonly recommended approach is to use the indicative ratings of symptoms below the level of disability given by the American Spinal Injury Association Impairment Scale /modified from the Frankel classification/ (American Spinal Injury Association, 2000; Marino et al., 2008; Harvey and Graves, 2011).

Category A / complete spinal cord injury/ - no sensory or motor function is preserved in sacral segments $\mathrm{S} 4-\mathrm{S} 5$.

Category $\boldsymbol{B}$ /incomplete/ - sensory, but not motor, function is preserved below the neurologic level and extends through sacral segments S4-S5.

Category $\boldsymbol{C}$ /incomplete/ - motor function is preserved below the neurologic level, and most key muscles below the neurologic level have a muscle grade of less than 3.

Category $\boldsymbol{D}$ /incomplete/ - motor function is preserved below the neurologic level, and most key muscles below the neurologic level have a muscle grade that is greater than or equal to 3 .

Category $\boldsymbol{E}$ /normal/ - sensory and motor functions are normal.

When the spinal cord is transacted, we can also find other symptoms such as: drop in blood pressure, bradycardia, impaired thermoregulation, areflexia, anaesthesia, muscle atonia, plegia, paralytic ileus, or atonic bladder with urinary incontinence. The most serious respiratory dysfunction is when there is a direct relationship between the level of the cord injury and the degree of respiratory dysfunction. With high lesions /C1 or $\mathrm{C} 2 /$, vital capacity is only $5-10 \%$ of normal, and cough is absent, with lesions at C3 through C6, vital capacity is $20 \%$ of normal, and cough is weak and ineffective, with high thoracic cord injuries / T2 through T4/ vital capacity is 30$50 \%$ of normal, and cough is weak, with lower cord injuries, respiratory function and improves with injuries at T11 with minimal respiratory dysfunction. It is also important to note that determining the severity of injuries is relatively easy with preserved consciousness of injured individuals and difficult for unconscious individuals. In any case, we always treat these individuals the same way even if the damage to the spine and spinal cord is an estimate (Urdaneta and Layon, 2003; Ryken et al., 2013).

\section{Principles of First Aid}

This type of injury requires properly implemented first aid. The crucial principle is an accurate treatment process at the site of the injury and the nature of any subsequent transport to a medical facility. We must not forget that the injury itself might not violate the function of the spinal cord, but subsequent maladministration of first aid during extrication, carrying and manipulating the injured individual can lead to permanent damage.

Among the principles of professional aid we should mention adequate fixation and handling, solution of respiratory insufficiencies and failure, and any subsequent transport of the injured individual to a medical facility. In addressing immobilization, handling and transport, we must realize that, if possible, it is always best to keep an injured individual in the position in which he or she was found (not to perform any manipulation). It is essential to keep the injured individual /if not in a coma still and try to obtain all the relevant information about his or her injury, the formation mechanism, whether the injured individual was immediately moving after the accident and whether he or she was feeling any problems including possible respiratory insufficiency. All this information, together with a description of the disability, implemented procedures and first aid must be gathered for the specialists, usually paramedics, who provide better care for the injured. Only rarely do we have to proceed differently, for example, in a situation where you cannot assume rapid professional assistance, such as when the accident occurs in poorly accessible terrain. Instructions for first aid in these cases of extreme or inaccessible conditions are clear (Battlefield Advanced Trauma Life Support BATLS, 2004; Zhang et al., 2013; Shekhar and Khan, 2016). We must rescue the injured individual with the help of as many rescuers as possible and put him or her into a neutral position lying on their back, preferably on a hard surface (Manoach and Paladino, 2007).

For manipulating an individual with a suspected cervical spine injury in these cases, we use these fixation techniques: 
- Basic fixation - the rescuer firmly presses the trapezium muscle next to the head. The forearm can thereby form a solid surface, which the rescuer presses the head against with his other hand in the correct axial position. If we are unable to proceed this way, we could use different techniques in some cases, but we must always maintain the fixation of the head in the neutral position.

- Pulling the hair - the other hand or hands of other rescuers fixate the victim's head from the side to avoid any possible movements as much as possible, for example during the rapid extrication of individuals from a burning vehicle. In a critical situation, which may lead to respiratory failure, we might need to remove a helmet. One rescuer maintains the fixation of the head and neck in the neutral position by constantly pressing his hand against the mandible. The other rescuer removes the helmet by pulling the lower edge with hands. It is essential to avoid any bending forward or backward or rotation of the head during this procedure, so there is no spinal injury. Remember, with integral helmets we need to lift the visor as well as release the catch on the side of the helmet, allowing us to lift the chin spoiler up or to the side or to open it fully.

- "Rail touch technique" - the rescuer firmly presses the trapezium muscles of the victim with both hands, with thumbs pointing at the chest front, and with his forearms he fixates the head. This technique is typically used for fixation of the cervical spine during the transfer of the victim. Fixation with a neck collar is essential.

- During the necessary transfer of the victim we could stabilize the head using Lateral fixation - we could use for example a rolled-up jacket or blanket that we put around the victim's head in a horseshoe shape and we fix it to the stretcher using scarves, belts or bands, etc. We could prevent any movements of the head to the side by putting "blocks" on both sides of the head. We try to fix these blocks to the stretcher as well as the body using scarves, belts or bands. If we fix only the head, it could lead to further damage when we try to manipulate the victim.

- "Improvised collar" - which should be used only in extreme cases, e.g. inaccessible places with long transport of the victim. In this situation, we could use for example a magazine which we fold several times and wrap in a piece of cloth. Than we form the magazine into a letter "U" for which we could use our thigh and we attach it in front and tighten the loosened ends of the fabric (McNab, 2006). In the majority of "normal cases" it is recommended not to do so, because relatively large manipulation of the victim may lead to further damage of the head and cervical spine.

When providing first aid to injuries occurring in water /jumps, falls into unknown water/ we always extricate the victim in the supine position. At the same time, we try to keep the position of the cervical spine in a neutral position without leaning sideways. When the victim is experiencing respiratory arrest we must always begin resuscitation immediately in the water. Clearing the respiratory tract is performed by advancing the mandible and opening his/her mouth without bending the head backward. If we have appropriate equipment/usually only some members of the integrated rescue system are equipped/, we arrange transport of the victim to the nearest medical facility. We use a spinal frame, which is manufactured in two basic types, a one-piece spinal board or a divisible scoop frame. We provide the fixation of the head with a cervical collar to prevent movement in any direction and to help keep the airway free. These cervical collars are made of a variety of hard materials and it is important to attach them properly, so we use appropriate supportive body lines, i.e. mandible, sternum - the neck area. Two rescuers always work together. One of them fixates the head and cervical spine using a proper fixation technique, while the other attaches the cervical collar in such a way that the cervical spine is stabilized and on its axis (Schubl et al., 2016). For the purposes of head fixation, we could also use a "head immobilizer" which is made of expandable homogenous material with straps to help immobilize the victim's forehead and chin and to attach it to the spinal board or scoop frame.

The most effective technique for rescuing an injured individual with spinal trauma is the "system for recovery of the injured with a spinal fixation" (Muralidhar et al., 2014; Byung-Guk et al., 2015). It is a technical aid which gently yet sufficiently fixates the spine and enables subsequent manipulation of the victim while rescuing and transporting him/her. Roughly described, it is a kind of cloak with spine stiffening plates sewn into it. There are straps with clamps on the cloak / usually in a different colour/ to help with the whole body fixation - two for the head, three for the chest and abdomen and two for the hips. The entire system is attached quite simply. Two rescuers work together, the first one holding the head using a proper fixation technique attaches the cervical collar or other type of head immobilizer, while the other attaches the system so that the spine of the victim is also the central axis of the fixation system. There should be no gap between the neck and the fixation. Finally, all the straps need to be fastened. When providing first aid, we must not forget other serious consequences of this type of injury. If the spinal cord is damaged above the C3 segment, the victim is not capable of spontaneous breathing and we must immediately start resuscitation. We clear the respiratory tract with the head held straight, preferably by advancing the mandible (e.g. (Pysny et al., 2011; Monsieurs et al., 2015)). Very often the victim loses thermoregulatory ability. In a hot environment we try every possible method to keep the victim cool and on the other hand, in a cold environment we try to heat the victim's body with aluminium foil or at least a blanket.

\section{Conclusion}

Traumatic spinal injury is one of the most dangerous accidents that can occur during some classes taught at faculties of education focused on physical education and sports. Improperly provided first aid may ultimately endanger the life of an individual or leave permanent consequences that can limit the victim forever. Therefore, there is a strong emphasis on teaching appropriate first aid procedures for this type of injury in the Czech Republic. In this case, the aim is to obtain relevant expertise in this matter. Thus, every graduate of this field of study, i.e. not only a teacher or a coach but also every student should acquire the knowledge which will allow them to evaluate the situation related to this type of injury and any subsequently emerging clinical manifestations and simultaneously provide all the necessary procedures at a relatively good level, including the use of the "system for recovery of the injured with a spinal fixation". 


\section{References}

American Spinal Injury Association, 2000. International standards for neurological classifications of spinal cord injury. Chicago: American Spinal Injury Association.

Battlefield Advanced Trauma Life Support BATLS, 2004. Journal of the Royal Army Medical Corps, 150(1): 32-40.

Byung-Guk, K., D. Jin-Myoung and S. Dong-Eun, 2015. Treatment of thoracolumbar fracture. Asian Spine Journal, 9(1): 133-146. View at Google Scholar | View at Publisher

Donatelli, R., D. Dimond and M. Holland, 2012. Sport-specific biomechanics of spinal injuries in the athlete (Throwing Athletes, Rotational Sports, and Contact-Collision Sports). Clinics in Sports Medicine, 31(3): 381-396. View at Google Scholar |View at Publisher

Harvey, L. and D. Graves, 2011. International standards for the neurological classification of spinal cord injury. Journal of Physiotherapy, 57(2): 129. View at Google Scholar | View at Publisher

Manoach, S. and L. Paladino, 2007. Manual in-line stabilization for acute airway management of suspected cervical spine injury: Historical review and current questions review article. Annals of Emergency Medicine, 50(3): 236-245. View at Google Scholar|View at Publisher

Marino, R.J., L. Jones and S. Kirshblum, 2008. Reliability and repeatability of the motor and sensory examination of the international standards for neurological classification of spinal cord injury. Journal of Spinal Cord Medicine, 31(2): 166-170. View at Google Scholar View at Publisher

McNab, C.H., 2006. Př́ručka SAS. První pomoc pro přežití. Praha: Svojtka Co.

Monsieurs, K.G., J.P. Nolan, L.L. Bossaert, R. Greif, I.K. Maconochie, N.I. Nikolaou, G.D. Perkins, J. Soar, A. Truhlar, J. Wyllie and D.A. Zideman, 2015. European resuscitation council guidelines for resuscitation 2015: Section 1. Executive summary. Resuscitation, 95: 1-80. View at Google Scholar

Muralidhar, B.M., D. Hegde and P.S.B. Hussain, 2014. Management of unstable thoracolumbar spinal fractures by pedicle screws and rods fixation. Journal of Clinical and Diagnostic Research, 8(2): 12 1-123. View at Google Scholar $\mid$ View at Publisher

O’Dowd, J.K., 2007. Spine. In: T.P. Rüedi, R.E. Buckley, C.G. Moran (Eds.). AO principles of fracture management. Specific fractures. Stuttgart: Georg Thieme. pp: 933-948.

Patel, S.A., A.R. Vaccaro and J.A. Rihn, 2013. Epidemiology of spinal injuries in sports. Operative Techniques in Sports Medicine, 21(3): 146-151. View at Google Scholar | View at Publisher

Pysny, L., L. Hajerova Mullerova and J. Pysna, 2011. First aid in outdoor activities - emergency resuscitation. Journal of Outdoor Activities, $5(2): 88-98$.

Ryken, T.C., R.J. Hurlbert and M.N. Hadley, 2013. The acute cardiopulmonary management of patients with cervical spinal cord injuries. Neurosurgery, 72(2): 84-92. View at Google Scholar

Schubl, S.D., R.J. Robitsek and C. Sommerhalder, 2016. Cervical spine immobilization may be of value following firearm injury to the head and neck. American Journal of Emergency Medicine, 34(4): 726-729. View at Google Scholar $\mid$ View at Publisher

Shekhar, H. and S. Khan, 2016. Cervical spine injuries. Orthopaedics and Trauma, 30(5): 390-401. View at Google Scholar

Urdaneta, F. and A.J. Layon, 2003. Respiratory complications in patients with traumatic cervical spine injuries: Case report and review of the literature. Journal of Clinical Anesthesia, 15(5): 398-405. View at Google Scholar |View at Publisher

Vaverka, M. and L. Hrabálek, 2002. Míšní poranění. Doporučené postupy pro praktické lékaře. Praha: Česká Lékařská Společnost Jana Evangelisty Purkyně.

Yoganandan, N., B.D. Stemper and R.D. Rao, 2013. Patient mechanisms of injury in whiplash-associated disorders. Seminars in Spine Surgery, 25(1): 67-74. View at Google Scholar | View at Publisher

Zhang, S., R. Wadhwa and J. Haydel, 2013. Spine and spinal cord trauma: Diagnosis and management. Neurologic Clinics, 31(1): 183-206. View at Google Scholar 